\title{
The Effect of Technological Progress on Economic Growth
}

\author{
Mohammad Alawin \\ University of Jordan \\ Kuwait University \\ Prince Al-Alwan \\ University of Jordan
}

\begin{abstract}
The aim of this study is to calculate the contribution of the technological progress to the Jordanian economic growth during the period (1976-2017). The model in this paper depends on Solo model, which employs technological progress as one of the productive elements that contributes to economic growth.The results show that the variables under consideration have a relationship in the long-run. This study concludes that the weakest factor that contributes to the growth in the Jordanian economy is advancesin technology. The low contribution of technology compared to other resources of production (capital and labor) could be attributed to excessive spending on technology in some years and to the exceptional improvement of the productivity of other resources of productionin other some years. These results indicate that more research, using different methods, should be carried out on this area.
\end{abstract}

Keywords: Technological Progress, Economic Growth, Labor, Capital, Jordan.

\section{Introduction}

Economic growth is considered an important indicator that reveals the standard of living for individuals; it is also an important objective of any government. Economic growth is a long phase that includes comprehensive procedures for economic development. Economic thought has gone through several phases to interpret the sources of growth. During one of these phases, the Solo model emerged in 1956 and introduced technology into the model to explain economic growth (Todaro, 2015). This model is referred to as the exogenous growth model.

Technological progress is an important goal for an economy to achieve; any country seeking high rates of economic growth needs technological progress. Economists agree on the importance of technological and technical progress for high levels of economic output.

Technology includes two aspects: tangible and intangible. Previous studies differed in their orientation for the definition of technology. Some researchers define technology as a physical aspect representing equipment and manufacturing, while others consider technology as intangible resources, such as knowledge and experience. Others combine the two previous definitions, i.e., tangible and the intangible components.

The importance of technology appears clear through its application in different economic fields. Some empirical studies emphasize the major contribution of technological progress, along with labor and capital, on economic growth(Ranis, 2011).In addition, the issue of improving technology through national R\&D projects appears to be important for improving the economy as a whole(Dong-Hoet al., 2015).

Previous studies refer to the topic of advances in technology and economic growth in more than one way. Some previous studies concentrate on measuring the effect of advances in technology on economic growth (Ranis, 2011) and (Fazari, 2009). Other studies like (Hamdan, 2013), (Tahari, 2004), and (Adak, 2009) focus on analyzingall sources of economic growth.

Previous studies rely on different approaches to achieve their goals. Some use an inductive approach in the economic analysis of qualitative and quantitative terms, using linear multiple regressions. Other studies depend on the descriptive approach, using social survey. Some studies employ the Solo model, which is based on CobbDouglas production function, while other studies use time-series analysis. Previous studies cover different geographical areas, such as Egypt, Algeria, Oman, Saudi Arabia, Palestine, South Africa, Malaysia, Indonesia and Turkey. This topic has not been covered in the manner and methodology used here in Jordan, to the best of our knowledge. 
Some of the results of prior studies indicate that economic growth relies heavily on technological advances. Other studies point out that economic growth depends mainly on labor and capital. This study estimates how advances in technology would add to the growth in the Jordanian economy, as well as estimating the impact of other production inputs specifically labor and capitalon economic growth. This study is divided into four sections. Section 1 presents an introduction along with addressing the theoretical framework and discusses the previous economic literature; and Section 2 includes the methodology. Section 3 presents the contribution of technology to economic growth, and Section 4 gives the findings and recommendations of the study.

\section{Methodology}

This study aims to determine the contribution of technological advances to economic growth in Jordan, based on time-series analysis. Specifically, the study will use an economic model that combines the study variables and test whether the variables have unit root or they are stationary. After that we test for the co integration among variables, and finally estimate the effect of technological advances in economic growth in Jordan for the time period (1976-2017).

The study relies on a Cobb-Douglas production function to determine the effect of technological advances to economic growth. This function includes the following variables: physical capital (K), labor (L) and technological progress $(\mathrm{A})$. This function is represented in the following equation:

$$
R G D P=A K^{\alpha} L^{\beta}
$$

where $R G D P$ is real GDP, $\alpha$ s tands for the elasticity of the production input "capital", and $\beta$ stands for the elasticity of the production input "labor".After taking the natural logarithm of both sides of equation (1), it becomes:

$$
\operatorname{Ln} R G D P=\operatorname{Ln} A+\alpha \operatorname{Ln} K+\beta \operatorname{Ln} L .
$$

If we let $(\operatorname{Ln} A)$ represent residuals and express technology(Abu-Mudallala and Hamdan, 2011), then equation (2) becomes:

$$
\text { Ln } R G D P=\alpha \operatorname{Ln} K+\beta \operatorname{Ln} L \quad+\varepsilon
$$

Where $\varepsilon$ represents the residual term, which represents technological progress. This study uses annual time-series data for the period 1976 to 2017. The data sources include the Central Bank of Jordan, the Department of Statistics, and the National Center for Human Resources Development. The following tests and techniques are utilized for the methodology of this study:

\subsection{Statistical Descriptive of the Variables}

Table 1 shows the statistical illustration of the variables. The findings of the Jarque-Bera statistic prove that the data are normally distributed, given that using the hypothesis of normal distribution was accepted at a $10 \%$ level.

Table 1:The Results of the Descriptive Tests for the Variables

\begin{tabular}{|l|l|l|l|}
\hline & L & K & RGDP \\
\hline Mean & 845422.9 & 2551.342 & 5310.011 \\
\hline Maximum & 1440489.0 & 33671.900 & 10812.800 \\
\hline Minimum & 356748.0 & 193.400 & 1689.400 \\
\hline Std. Dev & 339698.7 & 5441.617 & 2621.046 \\
\hline Skewness & 0.079 & 5.118 & 0.794 \\
\hline Kurtosis & 1.727 & 29.717 & 2.465 \\
\hline Jarque-Bera & 2.607 & 4.144 & 4.449 \\
\hline Probability & 0.272 & 0.126 & 0.108 \\
\hline Observations & 38 & 38 & 38 \\
\hline
\end{tabular}

\subsection{Unit Root Test}

Economic variables are exposed to changes affecting their stationary and trend over time. It is difficult to use the data in the analysis without verifying the stationary of all data. It is possible to use the method of Least Square (OLS)for the variables at their levels if the variables don't have unit root. However, if the data have unit root or become stationary after taking the first difference, then it is possible for the variables to be co integrated. In effect, using OLS without verifying that variables are cointegrated may lead to a spurious regression. This paper uses Augmented Dickey Fuller (ADF) to check for the unit root. Table 2 reveals the findings of ADF test. 
Table 2: The Results of Augmented Dickey-Fuller Test

\begin{tabular}{|l|l|l|l|l|}
\hline & \multicolumn{2}{|l|}{ Level } & \multicolumn{2}{l|}{ 1st Difference } \\
\hline & Constant & $\begin{array}{l}\text { Constant } \\
\text { \& Trend }\end{array}$ & Constant & $\begin{array}{l}\text { Constant } \\
\text { \& Trend }\end{array}$ \\
\hline GDP & -1.639 & -2.263 & $-3.448^{*}$ & $-3.457^{*}$ \\
\hline K & -1.045 & $-4.362^{*}$ & $-9.258^{*}$ & $-9.117^{*}$ \\
\hline L & -1.626 & -0.934 & $-4.814^{*}$ & $-5.028^{*}$ \\
\hline
\end{tabular}

(*) means we cannot accept the hypothesis (that the data are not stationarity) at $10 \%$ significance level or better.

The findings of the ADF test show that all variables are non-stationary at the level, whether the test equation includes an intercept and trend or merely an intercept. There was one exception; capital shows stationarity when a trend is included in the ADF test. The results reveal that all variables have shown stationarity at the first difference. The number of lag periods has to be chosen carefully, because including the optimal lags in the test is important for the creditability of the findings. The Akaike Information Criterion (AIC) reveals that the optimal lag time period to be included in the model is one period.

\subsection{The Cointegration Test}

The cointegration test is conducted using the Johansson method to find the degree of cointegration between the variables. We perform this test after checking the stationarity of the data. Accordingly, this technique is conducted on variables that become stationary when first difference is taken. The Johansen test includes two different tests, the trace and the maximum Eigen value. The null hypothesis is that there would be no co integration among the time series data. If the calculated value is bigger than the tabulated value at a specified significance level, this will lead to the rejection of the null hypothesis.

Table 3: The Results of Cointegration Test

\begin{tabular}{|l|l|l|l|}
\hline \multicolumn{3}{|l|}{ Johansen Maximum Likehood Cointegration Tests } \\
\hline Trace Test & $\mathrm{H}_{1}$ & Trace statistic & $\begin{array}{l}5 \% \\
\text { value }\end{array}$ \\
\hline $\mathrm{H}_{0}$ & $\mathrm{r} \geq 1$ & $37.30^{*}$ & 35.01 \\
\hline $\mathrm{r}=0$ & $\mathrm{r} \geq 2$ & 14.23 & 18.390 \\
\hline $\mathrm{r} \leq 1$ & $\mathrm{r} \geq 3$ & 3.41 & 3.884 \\
\hline $\mathrm{r} \leq 2$ & $\mathrm{H}_{1}$ & $\begin{array}{l}\text { Max. Eigenvalue } \\
\text { statistic }\end{array}$ & $\begin{array}{l}5 \% \\
\text { value }\end{array}$ \\
\hline Eigenvalue Test & $26.180^{*}$ & 24.254 \\
\hline $\mathrm{H}_{0}$ & $\mathrm{r}=1$ & 10.762 & 17.143 \\
\hline $\mathrm{r}=0$ & $\mathrm{r}=2$ & 3.442 & 3.844 \\
\hline $\mathrm{r} \leq 1$ & $\mathrm{r}=3$ &
\end{tabular}

The results (Table 3) show that the calculated values for each of the two tests are bigger than the tabulated values at $5 \%$ significance level. Consequently, the null hypothesis of no cointegration between the variables of the study will not be accepted. Therefore, the results show that the variables are connected in a long run relationship.

\subsection{Vector Error Correction Model}

This model could be used when we check for the degree of stationarity of the variables. If the data are stationary at the zero level, I(0), then we use the OLS method. However, if data are stationary after taking the first difference, I(1),then we cannot use the OLS method. In this case, we use the VECM model (Gujarati, 2011). Usually, we utilize this model to estimate the relationships among the variables in both the long-run and short-run. This model relies on the sign and the significance of the error correction term; if it is negative and significant, this proves a long-run relationship. The relation between the time-series data is calculated by the Vector Error Correction Model (VECM). The findings show a strong relationship among the variables. 
It was found that this coefficient equals to (-0.112) and statistically significant at the $5 \%$ level. This value suggests a causal relationship among labor, real GDP, and capital ${ }^{(1)}$. The findings of the cointegration test are shown in Table 4.

Table 4: Results of the Cointegration Model

\begin{tabular}{|l|l|}
\hline Variable & Coefficient \\
\hline LNK & 0.171 \\
\hline LNL & 0.640 \\
\hline C & 0.986 \\
\hline R-squared & 0.629 \\
\hline Adj. R-squared & 0.406 \\
\hline Sum sq. resids & 0.036 \\
\hline S.E. equation & 0.036 \\
\hline F-statistic & 2.824 \\
\hline
\end{tabular}

Table 4demonstrates that elasticity for capital $(\alpha)$ is 0.17 and the elasticity of labor $(\beta)$ is 0.63 . These two elasticity's will be utilized in calculating the effect of technology advances in economic growth.

\section{The effect of Technology advances in Economic Growth}

In this section, we will rely on the findings of the previous model estimation; we can identify the contribution of technological progress through equation (4) following (Snowdon and Vane, 2005):

$\Delta Y / Y=(\Delta A / A)+(\alpha) \Delta K / K+(\beta) \Delta L / L$

Equation (4) implies that the real GDP growth rate can be found by summing up the growth rates of three components: technological advances (A), capital $(\mathrm{K})$ and labor (L). Therefore, the technological advances contribution can be calculated as:

$(\Delta A / A)=\Delta Y / Y-(\alpha) \Delta \mathrm{K} / \mathrm{K}-(\beta) \Delta \mathrm{L} / \mathrm{L}$

We can conclude from Equation5 that the contribution of technological advances can be measured as growth in real GDP minus the total of the contributions of both labor and capital.

Using the values of $\alpha$ and $\beta$ calculated from the production function model, capital and labor contributions can be calculated as follows (Abu-Mudallala and Hamdan, 2011): (1) The contribution of capital will equal to $(\Delta \mathrm{K} / \mathrm{K})$ multiplied by $(\alpha)$. (2) The contribution of the labor equals $(\Delta \mathrm{L} / \mathrm{L})$ multiplied by $(\beta)$.

It is noted that both of these elasticity's, $\alpha$ and $\beta$, are driven from Table 4 . Therefore, the effect of technological advances to economic growth for Jordanis given by Appendix (1). The Appendix reveals that average contribution of technological advances in the rate of economic growth in Jordan is $0.92 \%$ during the period of 1977-2017. The highest contribution to technological advances was $15.6 \%$ in 1979. The contribution of technological advances to economic growth during this period was not always positive. The minimum contribution of technology was in 1984 with a negative impact of $16.42 \%$.

According to the results of this model, the contribution of technology in economic growth seems surprising. In 13 years out of 37 years, the contribution of technology in economic growth was negative. This result could be attributed either to the excessive spending on technology in some years or to the outstanding performance of labor and capital in some years.

The largest share of input resources contributing to the economy goes for the labor. The average contribution of labor during the study period is $2.3 \%$.The maximum value of this contribution is $18.3 \%$ in 1985 .However, the lowest contribution of labor to economic growth was in 2010, where it reaches $-9.08 \%$. Appendix 1 also indicates that the capital contribution to economic growth was higher than the contribution of technology and less than the contribution of labor. The average capital contribution in economic growth during the study period reaches $2.0 \%$. The highest contribution of capital to economic growth was $10.8 \%$ in 1992 , while the lowest value was $-4.6 \%$ in 1985.

\footnotetext{
${ }^{(1)}$ The results of the VECM are available upon request.
} 


\section{Conclusion and Recommendations}

The goal of this research is to measure the contribution of technological advancesto Jordanian economic growth. To determine this amount of contribution, the study uses a time-series modelutilizing a Cobb-Douglas production function. In addition, this study employs several econometric tests to achieve its objectives. The results of this study are somewhat consistent with previous studies concerning the relationship between inputs and the growth rate of the economy. The findings of this study show that the average contribution of technological advances, labor, and capital to the growth of the economy, during the study period, are $0.92 \%, 2.33 \%$, and $2.0 \%$, respectively. These results suggest that labor and capital are still the most effective factors of production, especially for countries like Jordan.

\section{References}

Todaro, M. \&Smith, S. (2015). Economic Development.(12 ${ }^{\text {th }}$ Ed.). New York: Pearson.

Ranis, G.(2011). Technology and Human Development. Center Discussion Paper, Economic Growth Center, 1004.

Dong-Ho, S., Mi-sun,K.,Byeong-Hee,L., \& Jae-Soo,K. (2015). Factor Analysis for Improved Commercialization of Technologies Developed on Korea National R\&D Projects. Indian Journal of Science and Technology, 8(S9), 405-414.

Fazari, M. (2009). The Impact of Contemporary Technological Revolution on the Evaluation of Programs and Policies for Human Resources Management. PhD thesis, Damascus: Damascus University.

Hamdan,B.(2013). The Effect Employment on Economic Growth in Palestinian. The Journal of Al-Azhar University in Gaza- Humanities Series,15(1), 23-52.

Tahari, A., Ghura, D., \&Akitoby, B., \&Brou-Aka, E. (2004).Sources of Growth in Sub-Saharan Africa.International Monetary Fund Working Paper, WP/04/176.

Adak, M. (2009). Total Factor Productivity and Economic Growth. Istanbul Ticaret University Sosyal Bilimler Dergisi, 8(15): 49-56.

Abu-Mudallala, S. \&Hamdan, B. (2014). Measuring the Contribution of Technological Progress on the Palestinian Economy. Jordan Journal of Applied Science-Humanities Series, 16(1), 33-53.

Gujarati, D. \& Porter, D. (2009). Basic Econometrics.(5 ${ }^{\text {th }}$ ed).New York: Mc Grow-hill Irwin.

Snowdon,B. \&Vane, H.(2005). Modern Macroeconomics: Its Origins, Development and Current State. Massachusetts: Edward Elgar Publication Company. 


\section{Appendix 1: The Contributions of the Factors of Production in the Economic Growth}

\begin{tabular}{|c|c|c|c|c|c|c|c|c|}
\hline Year & $\Delta \mathrm{Y} / \mathrm{Y}$ & A & $\Delta \mathrm{K} / \mathrm{K}$ & $\alpha \Delta \mathrm{K} / \mathrm{K}$ & $\beta$ & $\Delta \mathrm{L} / \mathrm{L}$ & $\beta \Delta \mathrm{L} / \mathrm{L}$ & $\Delta \mathrm{A} / \mathrm{A}$ \\
\hline 1977 & 8.30 & 0.17 & 0.44 & 7.43 & 0.64 & 0.02 & 1.97 & -1.10 \\
\hline 1978 & 14.68 & 0.17 & -0.05 & -0.91 & 0.64 & 0.02 & 2.05 & 13.53 \\
\hline 1979 & 20.80 & 0.17 & 0.18 & 3.02 & 0.64 & 0.02 & 2.14 & 15.64 \\
\hline 1980 & 11.19 & 0.17 & 0.40 & 6.75 & 0.64 & 0.02 & 2.14 & 2.29 \\
\hline 1981 & 17.18 & 0.17 & 0.54 & 9.18 & 0.64 & 0.02 & 2.07 & 5.93 \\
\hline 1982 & 7.03 & 0.17 & -0.02 & -0.41 & 0.64 & 0.02 & 2.05 & 5.38 \\
\hline 1983 & -2.22 & 0.17 & -0.09 & -1.59 & 0.64 & 0.02 & 1.99 & -2.61 \\
\hline 1984 & 4.29 & 0.17 & -0.03 & -0.54 & 0.64 & 0.02 & 1.91 & 2.91 \\
\hline 1985 & -2.71 & 0.17 & -0.27 & -4.65 & 0.64 & 0.18 & 18.37 & -16.42 \\
\hline 1986 & 5.50 & 0.17 & 0.07 & 1.21 & 0.64 & 0.03 & 3.08 & 1.21 \\
\hline 1987 & 2.33 & 0.17 & 0.16 & 2.73 & 0.64 & 0.02 & 2.00 & -2.41 \\
\hline 1988 & 1.46 & 0.17 & 0.03 & 0.55 & 0.64 & -0.02 & -2.29 & 3.20 \\
\hline 1989 & -10.73 & 0.17 & 0.06 & 1.00 & 0.64 & 0.00 & 0.02 & -11.75 \\
\hline 1990 & -0.27 & 0.17 & 0.51 & 8.65 & 0.64 & 0.01 & 1.49 & -10.42 \\
\hline 1991 & 1.61 & 0.17 & -0.13 & -2.24 & 0.64 & 0.02 & 2.48 & 1.37 \\
\hline 1992 & 14.35 & 0.17 & 0.64 & 10.83 & 0.64 & 0.11 & 10.62 & $\begin{array}{l}-7.09 \\
\end{array}$ \\
\hline 1993 & 4.49 & 0.17 & 0.18 & 3.01 & 0.64 & 0.07 & 6.52 & -5.05 \\
\hline 1994 & 4.97 & 0.17 & 0.02 & 0.34 & 0.64 & 0.02 & 1.91 & 2.72 \\
\hline 1995 & 6.20 & 0.17 & 0.07 & 1.21 & 0.64 & 0.06 & 5.51 & -0.52 \\
\hline 1996 & 2.09 & 0.17 & -0.04 & -0.60 & 0.64 & 0.00 & 0.24 & 2.45 \\
\hline 1997 & 3.31 & 0.17 & -0.12 & -2.01 & 0.64 & 0.00 & -0.23 & 5.55 \\
\hline 1998 & 3.01 & 0.17 & -0.07 & -1.26 & 0.64 & 0.00 & 0.18 & 4.09 \\
\hline 1999 & 3.39 & 0.17 & 0.02 & 0.31 & 0.64 & 0.02 & 1.65 & 1.43 \\
\hline 2000 & 4.24 & 0.17 & 0.08 & 1.30 & 0.64 & 0.01 & 1.18 & 1.77 \\
\hline 2001 & 5.27 & 0.17 & 0.00 & -0.02 & 0.64 & 0.02 & 1.88 & 3.41 \\
\hline 2002 & 5.78 & 0.17 & 0.02 & 0.32 & 0.64 & 0.01 & 0.99 & 4.47 \\
\hline 2003 & 4.16 & 0.17 & 0.10 & 1.76 & 0.64 & 0.01 & 1.35 & 1.06 \\
\hline 2004 & 8.57 & 0.17 & 0.47 & 8.00 & 0.64 & 0.05 & 5.30 & -4.74 \\
\hline 2005 & 8.15 & 0.17 & 0.38 & 6.39 & 0.64 & 0.03 & 3.20 & -1.44 \\
\hline 2006 & 8.09 & 0.17 & -0.01 & -0.13 & 0.64 & 0.05 & 5.14 & 3.08 \\
\hline 2007 & 8.18 & 0.17 & 0.21 & 3.63 & 0.64 & 0.04 & 2.59 & 1.95 \\
\hline 2008 & 7.22 & 0.17 & 0.23 & 4.58 & 0.64 & 0.46 & 2.94 & -0.30 \\
\hline 2009 & 5.49 & 0.17 & -0.05 & -0.78 & 0.64 & 0.02 & 1.62 & 4.65 \\
\hline 2010 & 2.31 & 0.17 & 0.08 & 1.30 & 0.64 & -0.09 & -9.09 & 10.10 \\
\hline 2011 & 2.59 & 0.17 & -0.01 & -0.11 & 0.64 & 0.01 & 0.78 & 1.92 \\
\hline 2012 & 2.65 & 0.17 & 0.07 & 1.19 & 0.64 & 0.01 & 0.88 & 0.59 \\
\hline 2013 & 2.83 & 0.17 & 0.33 & 5.55 & 0.64 & 0.00 & -0.23 & -2.49 \\
\hline 2014 & 3.10 & 0.17 & 11.40 & 1.94 & 0.64 & 2.00 & 1.28 & -0.12 \\
\hline 2015 & 2.38 & 0.17 & -3.45 & -0.59 & 0.64 & 2.40 & 1.54 & 1.43 \\
\hline 2016 & 2.20 & 0.17 & -6.29 & -1.07 & 0.64 & 2.30 & 1.47 & 1.80 \\
\hline 2017 & 2.10 & 0.17 & 3.02 & 0.51 & 0.64 & 1.54 & 0.99 & 0.60 \\
\hline
\end{tabular}

